\title{
Hunger as a driver of depressive symptoms: Optimising responses to mental health aspects of the COVID-19 pandemic
}

The COVID-19 pandemic has had major implications for mental health, and much has been written about clinical interventions and health policy to address this. In South Africa (SA) and other low- and middle-income countries, this mental health burden may have unique aspects. In the international literature, symptoms of depression may be driven by experiences of food insecurity and hunger. In the context of the pandemic, in which food insecurity and hunger are on the rise, hunger as a driver of poor mental health in the pandemic warrants further discussion.

\section{Hunger and mental health}

Child hunger and malnutrition in SA were widespread even before the pandemic, with more than a quarter of children under 5 years of age (27\%) being stunted in 2016. ${ }^{[1]}$ Furthermore, child mortality audits show that almost a third of children who die are severely malnourished. ${ }^{[2]}$ The link between hunger and mental illness is well known. Compared with preschool children with no hunger, severe hunger is associated with higher levels of chronic illness and internalising behaviour problems, ${ }^{[3]}$ and caregivers of hungry children have more mental health problems (post-traumatic stress disorder in this study). ${ }^{[3]}$ Both food insecurity and hunger are associated with depression, ${ }^{[4-6]}$ anxiety ${ }^{[6,7]}$ and suicidal ideation and attempts. ${ }^{[4,8]}$

\section{Findings from the pandemic surveys in SA}

To quantify the impact of the COVID-19 pandemic on South Africans, the National Income Dynamics Study - Coronavirus Rapid Mobile Survey (NIDS-CRAM) was initiated. NIDS-CRAM is a broadly nationally representative panel survey of 7000 SA adults. In each of the three waves of data collection to date, all participants were phoned and asked about income and employment, household welfare, hunger (both household hunger and child hunger specifically), receipt of grants, and knowledge and behaviour related to COVID-19.

The first wave of the NIDS-CRAM, administered during May and June 2020, showed that there had been a drastic increase in both adult and child hunger relative to pre-pandemic household surveys, and that almost half of all households (47\%) had run out of money for food during April 2020. ${ }^{[9]}$ Twenty-two percent reported that someone in the household had gone hungry during the past 7 days because there was not enough food, and - in households with children $15 \%$ reported that a child had gone hungry in the past week. ${ }^{[10]}$ The NIDS-CRAM data also showed that both hunger and hunger severity increase the likelihood of screening positive for depressive symptoms, and that this likelihood reduces with the number of social grants a household receives. Moreover, this trend was stronger for households in the bottom socioeconomic quintiles, indicating that those who are most hungry are most vulnerable to depressive symptoms. ${ }^{[11]}$

Results from NIDS-CRAM's third wave of data collection (in November and December 2020) indicate that household hunger continued to be positively associated with poor mental health. Worryingly, this relationship seems to have strengthened between wave 2 and wave 3, despite the lifting of lockdown restrictions in the interim. ${ }^{[12]}$ Of those individuals who experienced hunger 'every day' in the past 7 days, two-thirds (67\%) screened positive for depressive symptoms. ${ }^{[1]}$ Further, it is clear from the NIDS-CRAM data that certain sectors of the population are most at risk of hunger and of mental health problems, and of the mental health problems associated with hunger - predominantly poor black African women with children. ${ }^{[9]}$

Two relevant studies examined hunger and mental health among prospective and new mothers. Pregnant women, and new mothers and their young babies, may be particularly vulnerable to hunger. The Maternal and Child Health (MATCH) survey ${ }^{[13]}$ showed that, of 2214 mothers responding to hunger and mental health items delivered via the MomConnect mobile phone platform, 350 (16\%) reported that they had gone to bed hungry at least once in the past week, $11 \%$ reported going to bed hungry for one to two nights, and $5 \%$ reported going to bed hungry for three or more nights. New and prospective mothers who reported going to bed hungry for three or more nights in the week were five times more likely to say that they felt hopeless, down or depressed 'most days' compared with those not experiencing hunger (36\% v. $8 \%)$. The mental anguish of mothers experiencing their own child's hunger cannot be underestimated.

In a second survey conducted as part of Grow Great's CoCare study, ${ }^{[14]}$ pregnant women living in disadvantaged communities of Western Cape Province experienced high levels of hunger during the months following initiation of SA's national COVID-19 lockdown: $39 \%$ reported going to bed hungry, and $22 \%$ reported that a child in their home had gone to bed hungry at least once during the week prior to their participation in the survey $(n=2618)$.

In both of these studies with a subsection of the SA population, rates of hunger and mental distress were comparatively higher than the broader NIDS-CRAM surveys with the general population. ${ }^{[14]}$

\section{The way forward}

Given that poor mental health is associated with a range of negative outcomes, ${ }^{[15-18]}$ including early mortality ${ }^{[19]}$ we argue that disrupting the pathways from hunger to depressive symptoms should be a cornerstone of SA's social development and mental health policy. Much work on the impact of COVID-19 on mental health has addressed individual therapies and improving mental health services. Mental health system strengthening is of course vital, but we argue that in the context of a pandemic, and where healthcare human resources are scarce, the structural drivers of poor mental health are key. More work needs to be done to develop, implement and monitor policies that address the underlying mechanisms driving distress, such as hunger. Work on disasters has emphasised that key interventions are not medical or psychiatric; instead, the primary focus is on factors such as physical safety and food security. ${ }^{[20]}$ Similarly, in the South African COVID-19 context, the best mental health intervention may be providing targeted grants, increasing employment, and alleviating hunger.

Author contributions. XH drafted the manuscript. MT and NS were involved in the studies cited, and in conceptualising the paper and editing drafts. DJS contributed to workshopping the idea for the manuscript and in developing the final draft.

Funding. NIDS-CRAM was funded by Allan \& Gill Gray Philanthropy, the Michael \& Susan Dell Foundation, and the FEM Education Foundation.

Conflicts of interest. NS and MT both participated in the development of studies cited in this editorial (NIDS-CRAM and MATCH). NS is one of the leads on NIDS-CRAM. Both NS and MT have published on NIDS- 
CRAM and MATCH previously. MT has also been involved in the CoCare study mentioned in this paper, but only peripherally. Given the editorial nature of this article and the manner in which the findings are reported, we do not feel that these involvements constitute a conflict of interest for the authors.

\section{Xanthe Hunt}

Institute for Life Course Heath Research, Department of Global Health, Faculty of Medicine and Health Sciences, Stellenbosch University, Cape Town, South Africa xanthehuntwrites@gmail.com

\section{Dan J Stein}

South African Medical Research Council Risk and Resilience in Mental Disorders Unit, Department of Psychiatry, Faculty of Health Sciences, University of Cape Town, South Africa; and Neuroscience Institute, University of Cape Town, South Africa

\section{Nic Spaull}

Research on Socioeconomic Policy,

Department of Economics,

Faculty of Economic and Management

Sciences, Stellenbosch University,

Stellenbosch, South Africa

\section{Mark Tomlinson}

Institute for Life Course Health Research, Department of Global Health, Faculty of Medicine and Health Sciences, Stellenbosch University, Cape Town, South Africa; and School of Nursing and Midwifery, Queen's University, Belfast, Northern Ireland
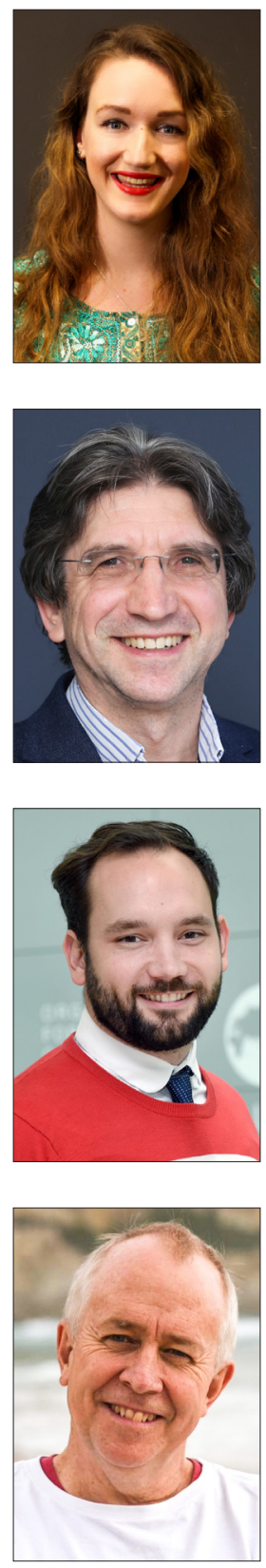

1. Statistics South Africa. South Africa Demographic and Health Survey 2016: Key Indicator Report. Pretoria: Stats SA, 2017. https://www.statssa.gov.za/publications/Report\%2003-00-09/Report\%20 03-00-092016.pdf (accessed 2 April 2021).

2. Bamford L, McKerrow N, Barron P, Aung Y. Child mortality in South Africa: Fewer deaths, but better data are needed. S Afr Med J 2018;108(3):25-32. https://doi.org/10.7196/SAMJ.2017.v108i3b.12779

3. Weinreb L, Wehler C, Perloff J, et al. Hunger: Its impact on children's health and mental health. Pediatrics 2002;110(4):1-9. https://doi.org/10.1542/peds.110.4.e41

4. McIntyre L, Williams JV, Lavorato DH, Patten S. Depression and suicide ideation in late adolescence and early adulthood are an outcome of child hunger. J Affect Disord 2013;150(1):123-129. https:// doi.org/10.1016/j.jad.2012.11.029

5. Huddleston-Casas C, Charnigo R, Simmons LA. Food insecurity and maternal depression in rural, low-income families: A longitudinal investigation. Public Health Nutr 2009;12(8):1133-1140. https://doi.org/10.1017/S1368980008003650

6. Hadley C, Patil CL. Food insecurity in rural Tanzania is associated with maternal anxiety and depression. Am J Hum Biol 2006;18(3):359-368. https://doi.org/10.1002/ajhb.20505

7. Whitaker RC, Phillips SM, Orzol SM. Food insecurity and the risks of depression and anxiety in mothers and behavior problems in their preschool-aged children. Pediatrics 2006;118(3):e859-e868. https://doi.org/10.1542/peds.2006-0239

8. Koyanagi A, Stubbs B, Oh H, et al. Food insecurity (hunger) and suicide attempts among 179,771 adolescents attending school from 9 high-income, 31 middle-income, and 4 low-income countries: A cross-sectional study. J Affect Disord 2019;248:91-98. https://doi.org/10.1016/j.jad.2019.01.033

9. Bridgman G, van der Berg S, Patel L. Hunger in South Africa during 2020: Results from wave 2 of NIDS-CRAM. Department of Economics, Stellenbosch University, 30 September 2020. https:// cramsurvey.org/wp-content/uploads/2020/09/3.-Bridgman-G.-Van-der-Berg-S.---Patel-L.-2020Hunger-in-South-Africa-during-2020-Results-from-Wave-2-of-NIDS-CRAM.pdf (accessed 30 March 2021).

10. Van der Berg S, Zuze L, Bridgman G. The impact of the coronavirus and lockdown on children's welfare in South Africa: Evidence from NIDS-CRAM wave 1. Department of Economics, Stellenbosch University, 15 July 2020. https://cramsurvey.org/wp-content/uploads/2020/07/Vander-Berg-Coronavirus-Lockdown-and-Children-1.pdf (accessed 14 April 2021)

11. Oyenubi A, Kollamparambil U. COVID-19 and depressive symptoms in South Africa: Results from wave 2 of NIDS-CRAM. Department of Economics, Stellenbosch University, 30 September 2020. https://cramsurvey.org/wp-content/uploads/2020/09/12.-Oyenubi-A.-_-Kollamparambil-U.-2020COVID-19-and-depressive-symptoms-in-South-Africa.pdf (accessed 30 March 2021)

12. Oyenubi A, Kollamparambil, U. How has the easing of lockdown influenced depressive symptoms in South Africa? Results from wave 3 of NIDS-CRAM. Department of Economics, Stellenbosch University, 17 February 2021. https://cramsurvey.org/wp-content/uploads/2021/02/9.-Oyenubi-A.Kollamparambil-U.-2021-How-has-the-easing-of-lockdown-influenced-depressive-symptoms-inKollamparambil-U.-2021-How-has-the-easing-of-lockdown-influenced-depressive-symptoms-in-
South-Africa.pdf (accessed 30 March 2021). South-Africa.pdf (accessed 30 March 2021)

Spaull N, Tomlinson M. Covid-19: SA speaks maternal hunger \& mental health. Financial Mail, 16 - 22 July 2020:1.

14. Matlwa Mabaso K, Laurenzi C, Menyatsoe M, Gemmell K, Manda S, Tomlinson M. Impact of COVID-19 on wellbeing of pregnant women in 7 neighbourhoods in the Western Cape. Johannesburg. Grow Great Campaign, March 2021. https://www.growgreat.co.za/wp-content/ uploads/2021/03/GG-COCARE-REPORT-final-1.pdf (accessed 14 April 2021).

15. Kessler RC. The costs of depression. Psychiatr Clin 2012;35(1):1-14. https://doi.org/10.1016/j. psc.2011.11.005

16. Scott KM, Bruffaerts R, Tsang A, et al. Depression-anxiety relationships with chronic physical conditions: Results from the World Mental Health Surveys. J Affect Disord 2007;103(1-3):113-120. https://doi.org/10.1016/j.jad.2007.01.015

17. Lovejoy MC, Graczyk PA, O'Hare E, Neuman G. Maternal depression and parenting behavior: A meta-analytic review. Clin Psychol Rev 2000;20(5):561-592. https://doi.org/10.1016/s02727358(98)00100-7

18. Lund C, Cois A. Simultaneous social causation and social drift: Longitudinal analysis of depression and poverty in South Africa. J Affect Disord 2018;229:396-402. https://doi.org/10.1016/j. jad.2017.12.050

19. Gilman SE, Sucha E, Kingsbury M, Horton NJ, Murphy JM, Colman I. Depression and mortality in a longitudinal study: 1952 - 2011. CMAJ 2017;189(42):E1304-E1310. https://doi.org/10.1503/ in a longitu 170125

20. Hobfoll SE, Watson P, Bell CC, et al. Five essential elements of immediate and mid-term mass trauma intervention: Empirical evidence. Psychiatry 2007;70(4):283-315. https://doi.org/10.1521/ psyc.2007.70.4.283

S Afr Med J 2021;111(7):604-605. https://doi.org/10.7196/SAMJ.2021.v111i7.15754 